\title{
One-Step Green Synthesis of Metallic Nanoparticles Using Sodium Alginate
}

\author{
Jesus Valdez and Idalia Gómez \\ Laboratorio de Materiales I, Facultad de Ciencias Químicas, Centro de Laboratorios Especializados, \\ Universidad Autónoma de Nuevo León, Avenida Pedro de Alba, 66451 Monterrey, NL, Mexico
}

Correspondence should be addressed to Idalia Gómez; idaliagomezmx@yahoo.com.mx

Received 30 March 2016; Accepted 23 June 2016

Academic Editor: Nathan C. Lindquist

Copyright ( 92016 J. Valdez and I. Gómez. This is an open access article distributed under the Creative Commons Attribution License, which permits unrestricted use, distribution, and reproduction in any medium, provided the original work is properly cited.

\begin{abstract}
Metallic nanoparticles have been focus of research because of their characteristic properties, specifically the LSPR which can have wide applications in biomedical sciences and engineering. Currently, traditional physical and chemical methods can synthesize these nanoparticles but their disadvantages such as costs, time, effectiveness, and toxicity of precursors provide a wide range of problems for the synthesis of these nanoparticles. Recently, some natural polymers and organic compounds have been used for the synthesis of nanoparticles by green methods. In this study, we synthesize copper, silver, and gold nanoparticles using sodium alginate as reducing and stabilizing agent under microwave irradiation. The LSPR for each system was observed by UV-vis spectroscopy. Particle size distribution and zeta potential demonstrate the size and stability for these nanoparticles. FESEM and TEM microscopies have shown the size and morphology of these systems correlated with UV-vis, particle size distribution, and zeta potential analyses. The study demonstrates a rapid, facile, cheaper, and one-step green method of synthesis for these metallic nanoparticles being an alternative to the conventional methods used for synthesis of metallic nanoparticles.
\end{abstract}

\section{Introduction}

Metallic nanoparticles have been investigated because of their characteristic properties and applications in the biomedical sciences and engineering, plus the interest for use in nanotechnology. These nanoparticles such as gold, silver, and copper differ from bulk materials due to the optical response of the excitation of localized surface plasmon resonance (LSPR). This phenomenon is coherent oscillations of conduction electrons in the excited metal surface due to the interaction with electromagnetic radiation.

These oscillations provide a band of extinction in the range of infrared, visible, and ultraviolet spectrum. The spectral position (wavelength) of these phenomena is very sensitive to the type of metal, size, shape, and dielectric surrounding on the media [1].

This field of research is known as "plasmonics" [2-4] and has been under research due to potential applications in small devices such as sensors and photonic circuits and also in medical diagnostics and therapy [5-9].
However, obtaining these nanoparticles by chemical or physical methods is complicated due to the consumption of energy and time, costs of equipment, and the toxicity of chemicals.

There are certain ways of synthesizing metal nanoparticles by physical methods; the most typical syntheses are the nanospheres lithography (NL) [10] and the electron beam lithography [11]. The main disadvantages of these methods are the restriction on nanoparticles' morphology for NL and a low yield and high investment costs for the EBL method. These disadvantages are overcome by chemical methods [12], specifically the chemical reduction.

This method has the possibility of synthesizing nanoparticles with controlled shapes and sizes and it has been characterized by its rapid progress in recent years with synthesis of different morphologies like spheres [13], rods $[14]$, prisms $[15,16]$, cubes $[17,18]$, and discs $[19,20]$, among others [21]. This combination of shapes and sizes provides different response in their optical properties, which can be 
TABLE 1: Considered values for the experiments for each system.

\begin{tabular}{lccccccc}
\hline \multirow{2}{*}{ Ion } & \multicolumn{2}{c}{ MW time of reaction [min] } & \multicolumn{3}{c}{ Metal ion concentration [mM] } \\
& High & Middle & Low & High & Middle & Low & Maximum \\
\hline Gold & 3 & 2 & 1 & 10 & 0.2 & 0.004 & 12.9 \\
Silver & 3 & 2 & 1 & 10 & 0.2 & 0.004 & 10 \\
Copper & 3 & 2 & 1 & 10 & 0.2 & 0.004 & 8 \\
\hline
\end{tabular}

TABLE 2

\begin{tabular}{lcc}
\hline Experiment & Time of reaction & Metal ion concentration \\
\hline 1 & High & High \\
2 & High & Low \\
3 & High & Middle \\
4 & Low & High \\
5 & Low & Low \\
6 & Low & Middle \\
7 & Middle & High \\
8 & Middle & Low \\
9 & Middle & Middle \\
\hline
\end{tabular}

used in different applications, depending on the requirement or field of study.

Many of these syntheses are carried out using reducing agents such as sodium borohydride [22, 23], hydrazine [24], $\mathrm{N}, \mathrm{N}$-dimethylformamide [25], and other organic compounds $[12,26,27]$ providing nanoparticles with a high reactivity. However, many of these compounds are related to the toxicity and biological risk [28]. Similarly, the stabilizing agents used for the synthesis include organic molecules like triphenylphosphine [29], polyvinyl alcohol [30], and polyvinylpyrrolidone [31], which are toxic and difficult to dispose environmentally [32].

Recently, some natural polymers and organic compounds such as chitosan [33], starch [34, 35], polypeptides [36], heparin [37], and hyaluronic acid [38] have been used for the synthesis of nanoparticles by green methods. Some of these compounds have a dual role of both reduction and stabilization of metallic nanoparticles, allowing a one-step synthesis [39]. In this work, the synthesis of copper, silver, and gold nanoparticles is presented using sodium alginate under microwave irradiation. This green synthesis method allows a facile, rapid, and one-step synthesis of these nanoparticles.

\section{Materials and Methods}

2.1. Synthesis of Metallic Nanoparticles. The synthesis of these nanoparticles was planned according to the interaction of metal ions concentration, time of reaction in the microwave, and a specific $\mathrm{pH}$ value for each system (see Table 1).

Experiments were carried out considering all the interactions for each system as it is showed in Table 2 .

For preparing the 9 experiments, in a beaker, $90 \mathrm{~mL}$ of ethylene glycol, $6 \mathrm{~mL}$ of sodium alginate $10 \mathrm{mM}$, and $3 \mathrm{~mL}$ of $\mathrm{NaCO}_{3} 0.1 \mathrm{M}$ were added. Then the solution was mixed and the $\mathrm{pH}$ was adjusted at 11,10 , and 12.5 for copper, silver, and gold experiments, respectively. From this solution, $10 \mathrm{~mL}$ was taken and placed in a vial for performing the synthesis. This was repeated for the rest of the experiments.

Then, $1 \mathrm{~mL}$ of the solution of $\mathrm{CuSO}_{4} \cdot 5 \mathrm{H}_{2} \mathrm{O}, \mathrm{HAuCl}_{4}$, and $\mathrm{AgNO}_{3}$ was added for the respective concentration according to Table 2. Then, the beaker was placed in the microwave (MW).

After the heating in MW, the solution for each experiment and system was sonicated for $1 \mathrm{~min}$, and then it was analyzed using UV-visible (Beckman Coulter DU 800). The experiment with the best plasmonic absorption was selected in order to do the following characterizations: using a concentration of $10 \mathrm{mM}$ for all three metal ions and $2 \mathrm{~min}$. for copper and $1 \mathrm{~min}$ for silver and gold experiments.

2.2. Particle Size Distribution and Zeta Potential. Particle size distribution and zeta potential were measured using a Zetasizer (Nano-ZS; Malvern Instruments Ltd., Malvern, UK). The nanoparticles solutions were diluted in distilled water placing $50 \mu \mathrm{L}$ of the sample in $2 \mathrm{~mL}$ of distilled water with a $\mathrm{pH}$ of $6.58 \pm 0.23$.

2.3. FESEM and TEM Analysis. The characterization using FESEM was carried out using an aluminum substrate. It was polished and washed with distilled water and acetone for three times; then, a drop of the nanoparticles solution was placed on the substrate and the solvent was allowed to evaporate at room temperature and it was analyzed using JEOL JSM-7401f microscope (JEOL USA, Inc. MA, USA).

TEM analysis was performed using Zeiss EM 10C 10CR TEM (Carl Zeiss Meditec, Oberkochen, Germany) equipment. The nanoparticle solutions were sonicated for 10 seconds, and $10 \mu \mathrm{L}$ of each one was taken and then placed onto the copper grid (carbon-coated copper grid, 200 mesh) and dried at room temperature, and then it was analyzed by TEM.

\section{Results and Discussion}

3.1. Synthesis of Metallic Nanoparticles. UV-vis analyses for the synthesis of copper, silver, and gold nanoparticles are shown in Figure 1. The spectra for the experiments of copper at 1 and $3 \mathrm{~min}$ of reaction on $\mathrm{MW}$ for the three different concentrations of metal ion do not show any characteristic LSPR absorption of copper nanoparticles. However, at $2 \mathrm{~min}$ for the middle and high concentrations, LSPR at $600 \mathrm{~nm}$ is presented. This result concords with the reports on the literature about the LSPR absorption for spherical copper nanoparticles [40].

The presence of the LSPR absorption on the experiment with $2 \mathrm{~min}$ of reaction time is because for $1 \mathrm{~min}$ the time is not 


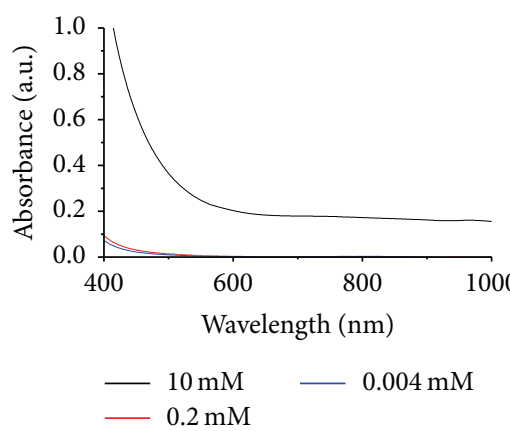

(a)

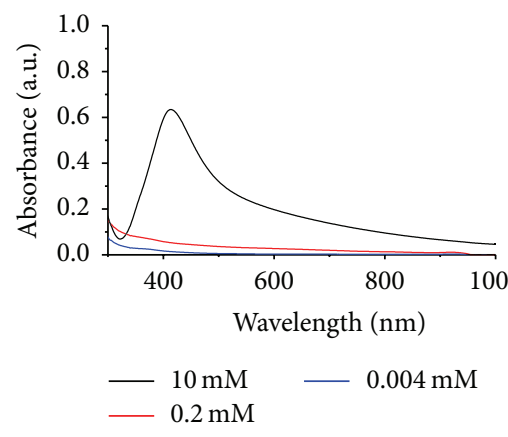

(d)

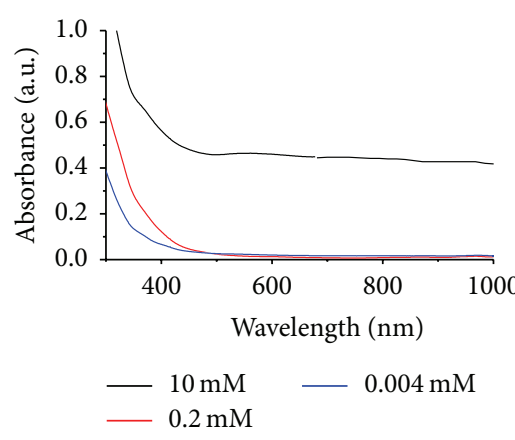

(g)

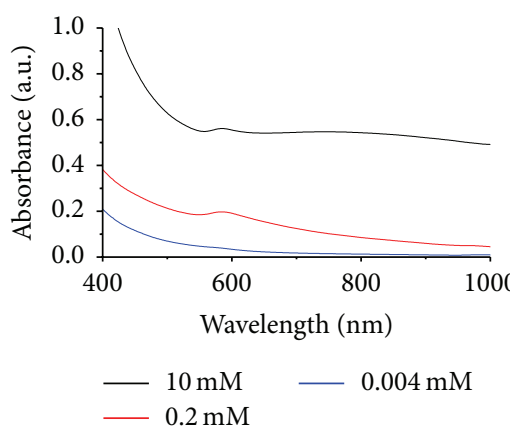

(b)
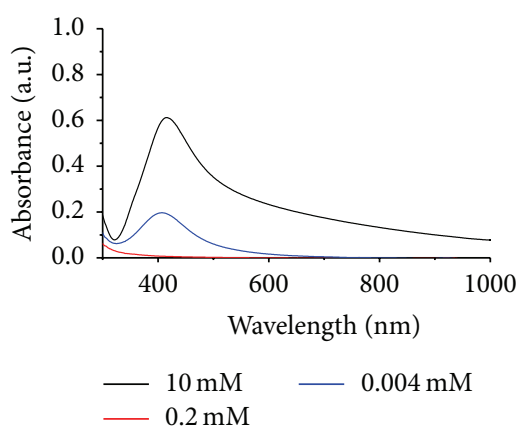

(e)

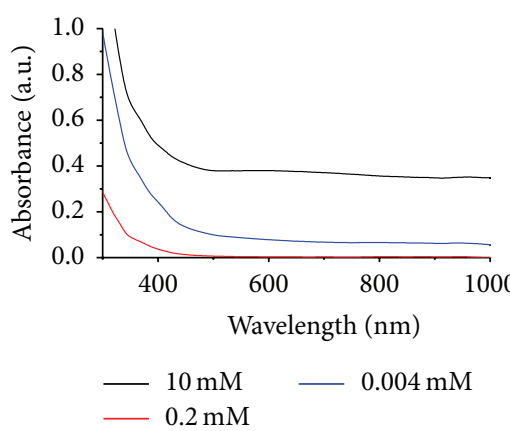

(h)

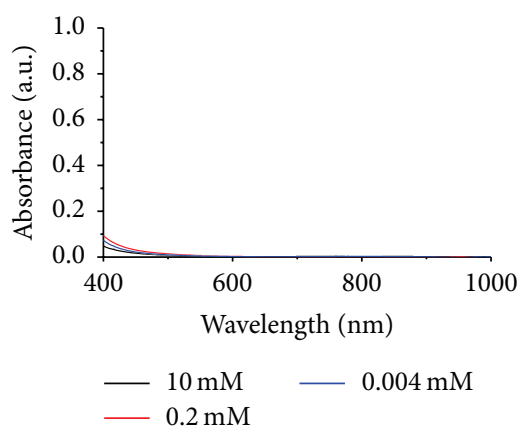

(c)

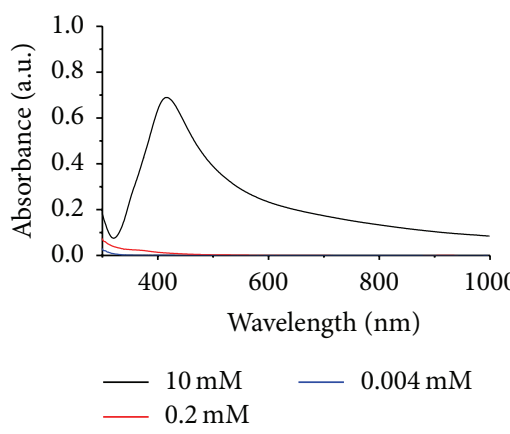

(f)

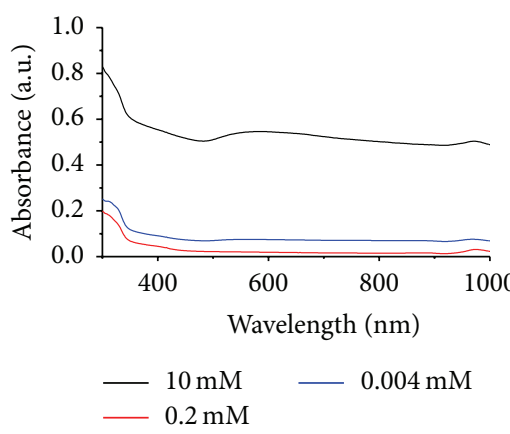

(i)

FIGURE 1: UV-vis analysis for the synthesis of copper (a, b, c), silver (d, e, f), and gold ( $g, h, i)$ nanoparticles using sodium alginate with a reaction time on $\mathrm{MW}$ of $3 \mathrm{~min}(\mathrm{a}, \mathrm{d}, \mathrm{g}), 2 \mathrm{~min}(\mathrm{~b}, \mathrm{e}, \mathrm{h})$, and $1 \mathrm{~min}(\mathrm{c}, \mathrm{f}, \mathrm{i})$. Black line is related to a concentration of $10 \mathrm{mM}$, red for $0.2 \mathrm{mM}$, and blue for $0.004 \mathrm{mM}$.

enough for the formation of these nanoparticles. The highest time of reaction induces a formation of black pellets and these could be composed of carbon from the decomposition of alginate molecule due to the heat on the reaction.

For silver experiments, the 3 different reaction times with the highest $(10 \mathrm{mM})$ concentration show the characteristic LSPR absorption at $400 \mathrm{~nm}$ for spherical silver nanoparticles [41]. Also, the experiment, exposed at 2 min of MW radiation with the lowest concentration, shows the same plasmon absorption.

In the case of gold experiments, the sample that only exhibits a characteristic absorption of a LSPR is when a concentration of $10 \mathrm{mM}$ and a time of $1 \mathrm{~min}$ in $\mathrm{MW}$ are used. This absorption is characteristic to spherical gold nanoparticles [42]. As well as copper nanoparticles, gold has the same problem at $3 \mathrm{~min}$ of reaction time.
3.2. Particle Size Distribution and Zeta Potential. The particle size distribution for copper, gold, and silver nanoparticles is shown in Figure 2. Copper experiment exhibits a size of $250 \mathrm{~nm}$ and for gold and silver nanoparticles, there is a similar pattern on the size distribution; there are two peaks: one is around $10 \mathrm{~nm}$ to $20 \mathrm{~nm}$, and the other one is presented on $150 \mathrm{~nm}$ and $185 \mathrm{~nm}$, respectively.

According to the LSPR absorption of copper, silver, and gold nanoparticles (Figure 1), it is not possible to assume that these sizes are related to the real size of nanoparticles. This is explained according to the size of nanoparticles; if these present a size higher than $100 \mathrm{~nm}$ (including the three systems), the LSPR absorption would be different and this phenomenon could be presented in a different wavelength [43].

In addition, it is reported that alginate could present hydrogen bonds [44] and this could be important because 


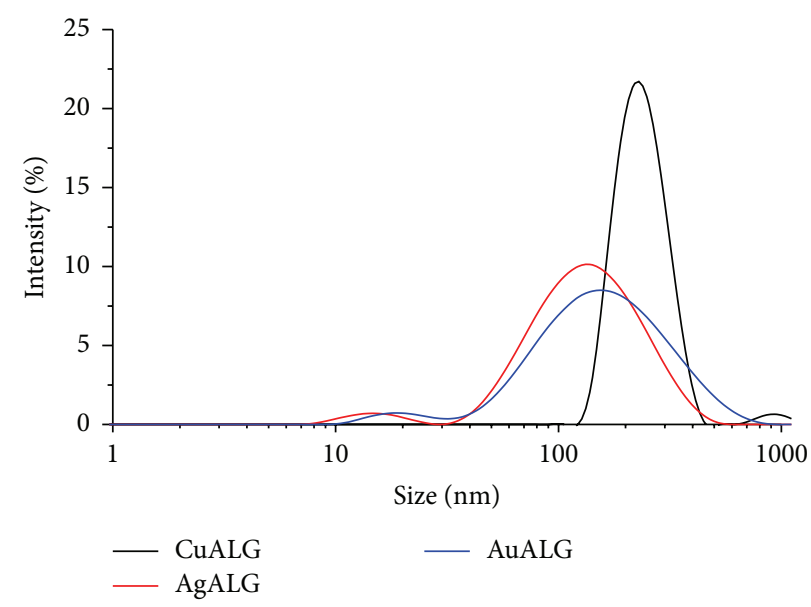

FIgURE 2: Particle size distribution for copper (black), silver (red), and gold (blue) nanoparticles.

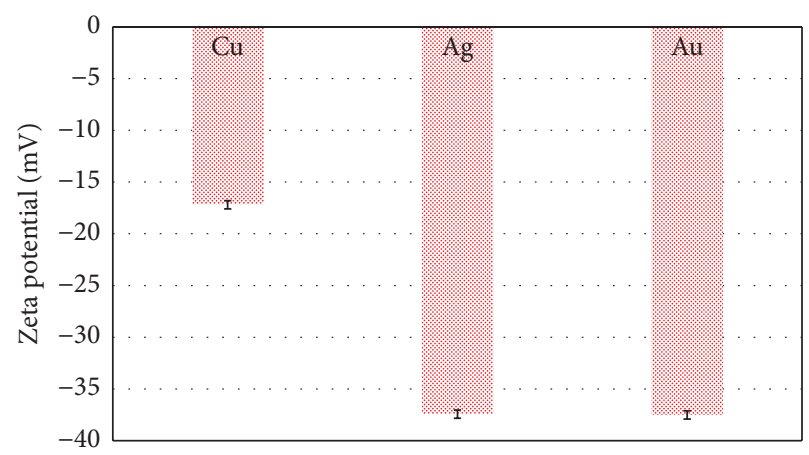

FIGURE 3: Zeta potential for the synthesized nanoparticles (red) dispensed in distilled water at pH of 6.58 measured at room temperature.

the alginate is presented on the surface of nanoparticles and this interaction could agglomerate more nanoparticles for making a bigger nanoparticle.

Also, for zeta potentials (Figure 3) for silver and gold nanoparticles were $-37 \pm 2.0 \mathrm{mV}$ and $-40 \pm 0.4 \mathrm{mV}$, these values are associated with the stability of these systems; for copper NPs this value was $-17.2 \pm 3.5 \mathrm{mV}$. It is important to say that this stability could be related to the agglomeration which occurs in all the systems where at a high zeta potential the agglomeration is less.

3.3. FESEM and TEM Analysis. Figure 4 shows the FESEM and TEM micrographs for copper, silver, and gold nanoparticles. Copper nanoparticles (Figure 4(a)) show a spherical morphology and these nanoparticles had a size less than $100 \mathrm{~nm}$ correlated with the LSPR absorption shown on UVvis analysis. In addition, these analyses demonstrate higher sizes attributed to agglomerates in the sample. The presence of these agglomerates is according to the zeta potential value and particle size distribution.

Silver nanoparticles exhibit an agglomeration (Figure 4(c)) but it is evident that these agglomerates are composed of smaller nanoparticles than $100 \mathrm{~nm}$ as it is observed in TEM analysis (Figure 4(d)). Similarly, gold nanoparticles exhibit sizes smaller than $100 \mathrm{~nm}$ and agglomerates in a linear way. In addition to copper characterization, these results are correlated with the previous characterizations as UV-vis, zeta potential, and particle size distribution.

\section{Conclusions}

An easy and simple one-step green synthesis of copper, silver, and gold nanoparticles using sodium alginate under microwave irradiation was reported. Synthesis was evaluated in terms of reaction time under microwave irradiation as well as concentration of metal ions. The LSPR characteristic for every system was proved using UV-nanoparticles having a correlation with the morphology observed using FESEM and TEM characterization likewise with the particle size distribution and zeta potential. This method proves to be rapid and green with a low cost from the chemicals to the synthesis of these nanoparticles and it could be an alternative to the conventional methods used for synthesis of metallic nanoparticles.

\section{Competing Interests}

The authors declare that there is no conflict of interests regarding the publication of this paper. 


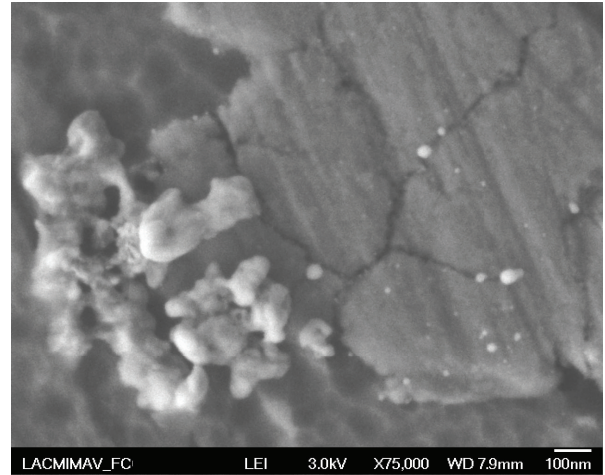

(a)

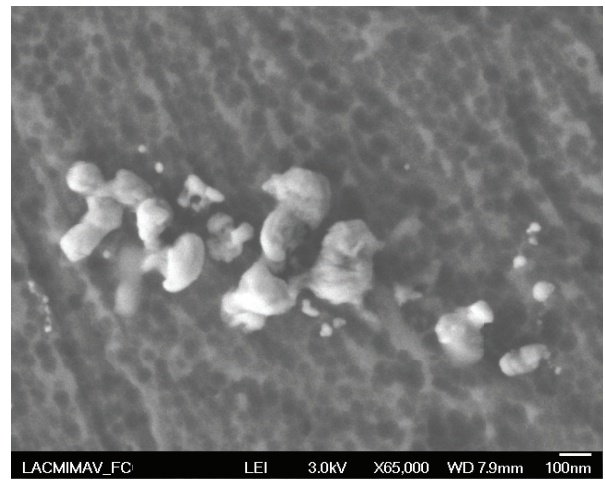

(c)

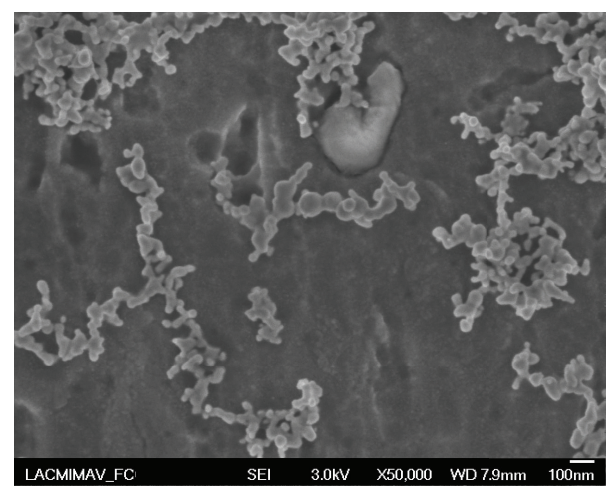

(e)

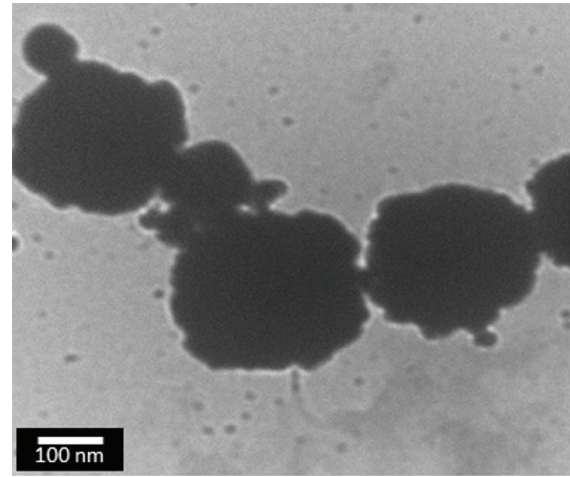

(b)

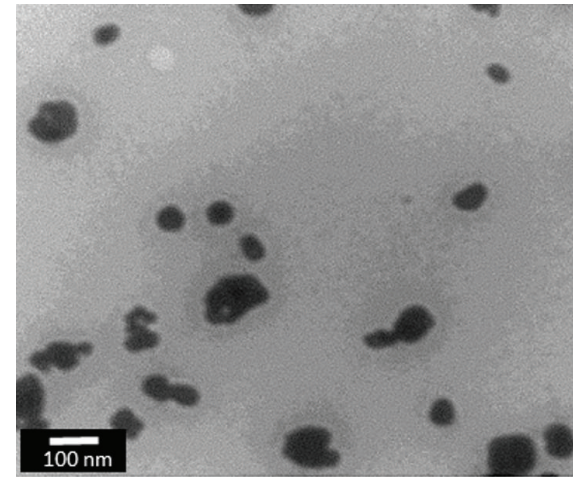

(d)

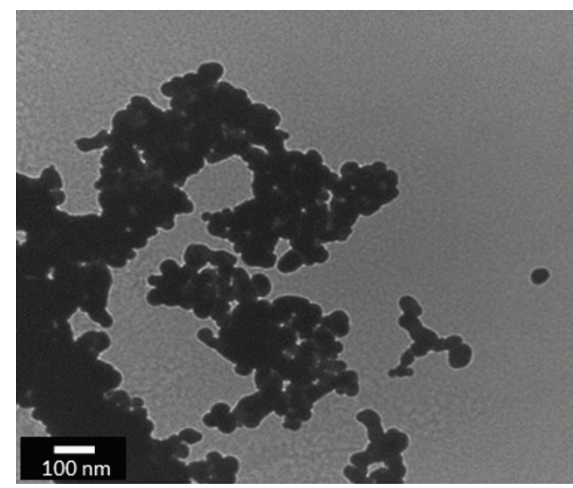

(f)

FIGURE 4: FESEM and TEM analyses for copper ((a) and (b)), silver ((c) and (d)), and gold ((e) and (f)) nanoparticles.

\section{Acknowledgments}

The authors are grateful for the financial support from Mexico's National Council of Science and Technology (Consejo Nacional de Ciencia y Tecnología).

\section{References}

[1] O. Hess, J. B. Pendry, S. A. Maier, R. F. Oulton, J. M. Hamm, and K. L. Tsakmakidis, "Active nanoplasmonic metamaterials," Nature Materials, vol. 11, no. 7, pp. 573-584, 2012.

[2] M. S. Khan and V. R. Chaudhari, "Morphological effect on fluorescence behavior of silver nanoparticles," Journal of Fluorescence, vol. 24, no. 3, pp. 751-757, 2014.
[3] T. Zhang, Y.-J. Song, X.-Y. Zhang, and J.-Y. Wu, "Synthesis of silver nanostructures by multistep methods," Sensors, vol. 14, no. 4, pp. 5860-5889, 2014.

[4] V. Amendola, O. M. Bakr, and F. Stellacci, "A study of the surface plasmon resonance of silver nanoparticles by the discrete dipole approximation method: effect of shape, size, structure, and assembly," Plasmonics, vol. 5, no. 1, pp. 85-97, 2010.

[5] Q. Zhao, R. Duan, J. Yuan, Y. Quan, H. Yang, and M. Xi, "A reusable localized surface plasmon resonance biosensor for quantitative detection of serum squamous cell carcinoma antigen in cervical cancer patients based on silver nanoparticles array," International Journal of Nanomedicine, vol. 9, pp. 10971104, 2014. 
[6] A. K. Rengan, M. Jagtap, A. De, R. Banerjee, and R. Srivastava, "Multifunctional gold coated thermo-sensitive liposomes for multimodal imaging and photo-thermal therapy of breast cancer cells," Nanoscale, vol. 6, no. 2, pp. 916-923, 2014.

[7] N. J. Wittenberg, B. Wootla, L. R. Jordan et al., "Applications of SPR for the characterization of molecules important in the pathogenesis and treatment of neurodegenerative diseases," Expert Review of Neurotherapeutics, vol. 14, no. 4, pp. 449-463, 2014.

[8] S. S. Lee and L. P. Lee, "Noninvasive label-free nanoplasmonic optical imaging for real-time monitoring of in vitro amyloid fibrogenesis," Nanoscale, vol. 6, no. 7, pp. 3561-3565, 2014.

[9] J. Y. Suh, C. H. Kim, W. Zhou et al., "Plasmonic bowtie nanolaser arrays," Nano Letters, vol. 12, no. 11, pp. 5769-5774, 2012.

[10] Z. Zhu, Q. Li, B. Bai, and S. Fan, "Reusable three-dimensional nanostructured substrates for surface-enhanced raman scattering," Nanoscale Research Letters, vol. 9, no. 1, article 25, 2014.

[11] C. Tabor, D. V. Haute, and M. A. El-Sayed, "Effect of orientation on plasmonic coupling between gold nanorods," ACS Nano, vol. 3, no. 11, pp. 3670-3678, 2009.

[12] J. I. Njagi and D. V. Goia, "Nitrilotriacetic acid: a novel reducing agent for synthesizing colloidal gold," Journal of Colloid and Interface Science, vol. 421, pp. 27-32, 2014.

[13] N. N. Long, L. Van Vu, C. D. Kiem et al., "Synthesis and optical properties of colloidal gold nanoparticles," Journal of Physics: Conference Series, vol. 187, no. 1, Article ID 012026, 2009.

[14] J. Pérez-Juste, I. Pastoriza-Santos, L. M. Liz-Marzán, and P. Mulvaney, "Gold nanorods: synthesis, characterization and applications," Coordination Chemistry Reviews, vol. 249, no. 1718, pp. 1870-1901, 2005.

[15] L. J. Sherry, R. Jin, C. A. Mirkin, G. C. Schatz, and R. P. Van Duyne, "Localized surface plasmon resonance spectroscopy of single silver triangular nanoprisms," Nano Letters, vol. 6, no. 9, pp. 2060-2065, 2006.

[16] X. Dong, X. Ji, J. Jing, M. Li, J. Li, and W. Yang, "Synthesis of triangular silver nanoprisms by stepwise reduction of sodium borohydride and trisodium citrate," The Journal of Physical Chemistry C, vol. 114, no. 5, pp. 2070-2074, 2010.

[17] S.-I. Choi, R. Choi, S. W. Han, and J. T. Park, "Synthesis and characterization of $\mathrm{Pt} 9 \mathrm{Co}$ nanocubes with high activity for oxygen reduction," Chemical Communications, vol. 46, no. 27, pp. 4950-4952, 2010.

[18] Y. Wang, Y. Zheng, C. Z. Huang, and Y. Xia, "Synthesis of Ag nanocubes $18-32 \mathrm{~nm}$ in edge length: the effects of polyol on reduction kinetics, size control, and reproducibility," Journal of the American Chemical Society, vol. 135, no. 5, pp. 1941-1951, 2013.

[19] S. Chen, Z. Fan, and D. L. Carroll, "Silver nanodisks: synthesis, characterization, and self-assembly," The Journal of Physical Chemistry B, vol. 106, no. 42, pp. 10777-10781, 2002.

[20] J. G. Son, S. W. Han, J.-S. Wi, and T. G. Lee, "Guided formation of sub-5 $\mathrm{nm}$ interstitial gaps between plasmonic nanodisks," Nanoscale, vol. 7, no. 18, pp. 8338-8342, 2015.

[21] M. Liu, Y. Zheng, S. Xie et al., "Facile synthesis of Pd-Ir bimetallic octapods and nanocages through galvanic replacement and co-reduction, and their use for hydrazine decomposition," Physical Chemistry Chemical Physics, vol. 15, no. 28, pp. 1182211829, 2013.

[22] K. Vimala, K. Samba Sivudu, Y. Murali Mohan, B. Sreedhar, and K. Mohana Raju, "Controlled silver nanoparticles synthesis in semi-hydrogel networks of poly(acrylamide) and carbohydrates: a rational methodology for antibacterial application," Carbohydrate Polymers, vol. 75, no. 3, pp. 463-471, 2009.

[23] U. T. Khatoon, K. V. Rao, J. V. R. Rao, and Y. Aparna, "Synthesis and characterization of silver nanoparticles by chemical reduction method," in Proceedings of the International Conference on Nanoscience, Engineering and Technology (ICONSET '11), pp. 97-99, Chennai, India, November 2011.

[24] W. G. Menezes, V. Zielasek, G. I. Dzhardimalieva et al., "Synthesis of stable AuAg bimetallic nanoparticles encapsulated by diblock copolymer micelles," Nanoscale, vol. 4, no. 5, pp. 1658$1664,2012$.

[25] H. Yamamoto, H. Yano, H. Kouchi, Y. Obora, R. Arakawa, and H. Kawasaki, "N,N-Dimethylformamide-stabilized gold nanoclusters as a catalyst for the reduction of 4-nitrophenol," Nanoscale, vol. 4, no. 14, pp. 4148-4154, 2012.

[26] D. Li, Q. He, and J. Li, "Smart core/shell nanocomposites: intelligent polymers modified gold nanoparticles," Advances in Colloid and Interface Science, vol. 149, no. 1-2, pp. 28-38, 2009.

[27] J. Fei, L. Gao, J. Zhao, C. Du, and J. Li, "Responsive helical self-assembly of $\mathrm{AgNO}_{3}$ and melamine through asymmetric coordination for Ag nanochain synthesis," Small, vol. 9, no. 7, pp. 1021-1024, 2013.

[28] Z. Zaheer and Rafiuddin, "Multi-branched flower-like silver nanoparticles: preparation and characterization," Colloids and Surfaces A: Physicochemical and Engineering Aspects, vol. 384, no. 1-3, pp. 427-431, 2011.

[29] S. U. Son, Y. Jang, K. Y. Yoon, E. Kang, and T. Hyeon, "Facile synthesis of various phosphine-stabilized monodisperse palladium nanoparticles through the understanding of coordination chemistry of the nanoparticles," Nano Letters, vol. 4, no. 6, pp. 1147-1151, 2004.

[30] A. N. Ananth, S. C. G. K. Daniel, T. A. Sironmani, and S. Umapathi, "PVA and BSA stabilized silver nanoparticles based surface-enhanced plasmon resonance probes for protein detection," Colloids and Surfaces B: Biointerfaces, vol. 85, no. 2, pp. 138-144, 2011.

[31] A. M. El Badawy, K. G. Scheckel, M. Suidan, and T. Tolaymat, "The impact of stabilization mechanism on the aggregation kinetics of silver nanoparticles," Science of the Total Environment, vol. 429, pp. 325-331, 2012.

[32] D. Li, Y. Cui, K. Wang, Q. He, X. Yan, and J. Li, “Thermosensitive nanostructures comprising gold nanoparticles grafted with block copolymers," Advanced Functional Materials, vol. 17, no. 16, pp. 3134-3140, 2007.

[33] D. Wei, W. Sun, W. Qian, Y. Ye, and X. Ma, “The synthesis of chitosan-based silver nanoparticles and their antibacterial activity," Carbohydrate Research, vol. 344, no. 17, pp. 2375-2382, 2009.

[34] B. Kumar, K. Smita, L. Cumbal, A. Debut, and R. N. Pathak, "Sonochemical synthesis of silver nanoparticles using starch: acomparison," Bioinorganic Chemistry and Applications, vol. 2014, Article ID 784268, 8 pages, 2014.

[35] M. A. El-Sheikh, "A novel photosynthesis of carboxymethyl starch-stabilized silver nanoparticles," The Scientific World Journal, vol. 2014, Article ID 514563, 11 pages, 2014.

[36] X. Yan, J. Blacklock, J. Li, and H. Möhwald, “One-pot synthesis of polypeptide-gold nanoconjugates for in vitro gene transfection," ACS Nano, vol. 6, no. 1, pp. 111-117, 2012. 
[37] M. D. P. Rodríguez-Torres, L. A. Díaz-Torres, P. Salas, C. Rodríguez-González, and M. Olmos-López, "UV photochemical synthesis of heparin-coated gold nanoparticles," Gold Bulletin, vol. 47, no. 1-2, pp. 21-31, 2014.

[38] N. Xia, Y. Cai, T. Jiang, and J. Yao, "Green synthesis of silver nanoparticles by chemical reduction with hyaluronan," Carbohydrate Polymers, vol. 86, no. 2, pp. 956-961, 2011.

[39] N. Vigneshwaran, R. P. Nachane, R. H. Balasubramanya, and P. V. Varadarajan, "A novel one-pot 'green' synthesis of stable silver nanoparticles using soluble starch," Carbohydrate Research, vol. 341, no. 12, pp. 2012-2018, 2006.

[40] T. M. D. Dang, T. T. T. Le, E. Fribourg-Blanc, and M. C. Dang, "Synthesis and optical properties of copper nanoparticles prepared by a chemical reduction method," Advances in Natural Sciences: Nanoscience and Nanotechnology, vol. 2, no. 1, Article ID 015009, 2011.

[41] S. Kheybari, N. Samadi, S. V. Hosseini, A. Fazeli, and M. R. Fazeli, "Synthesis and antimicrobial effects of silver nanoparticles produced by chemical reduction method," DARU Journal of Pharmaceutical Sciences, vol. 18, no. 3, pp. 168-172, 2010.

[42] X. Huang and M. A. El-Sayed, "Gold nanoparticles: optical properties and implementations in cancer diagnosis and photothermal therapy," Journal of Advanced Research, vol. 1, no. 1, pp. 13-28, 2010.

[43] S. Link and M. A. El-Sayed, "Size and temperature dependence of the plasmon absorption of colloidal gold nanoparticles," The Journal of Physical Chemistry B, vol. 103, no. 21, pp. 4212-4217, 1999.

[44] K. Y. Lee and D. J. Mooney, "Alginate: properties and biomedical applications," Progress in Polymer Science, vol. 37, no. 1, pp. 106126, 2012. 

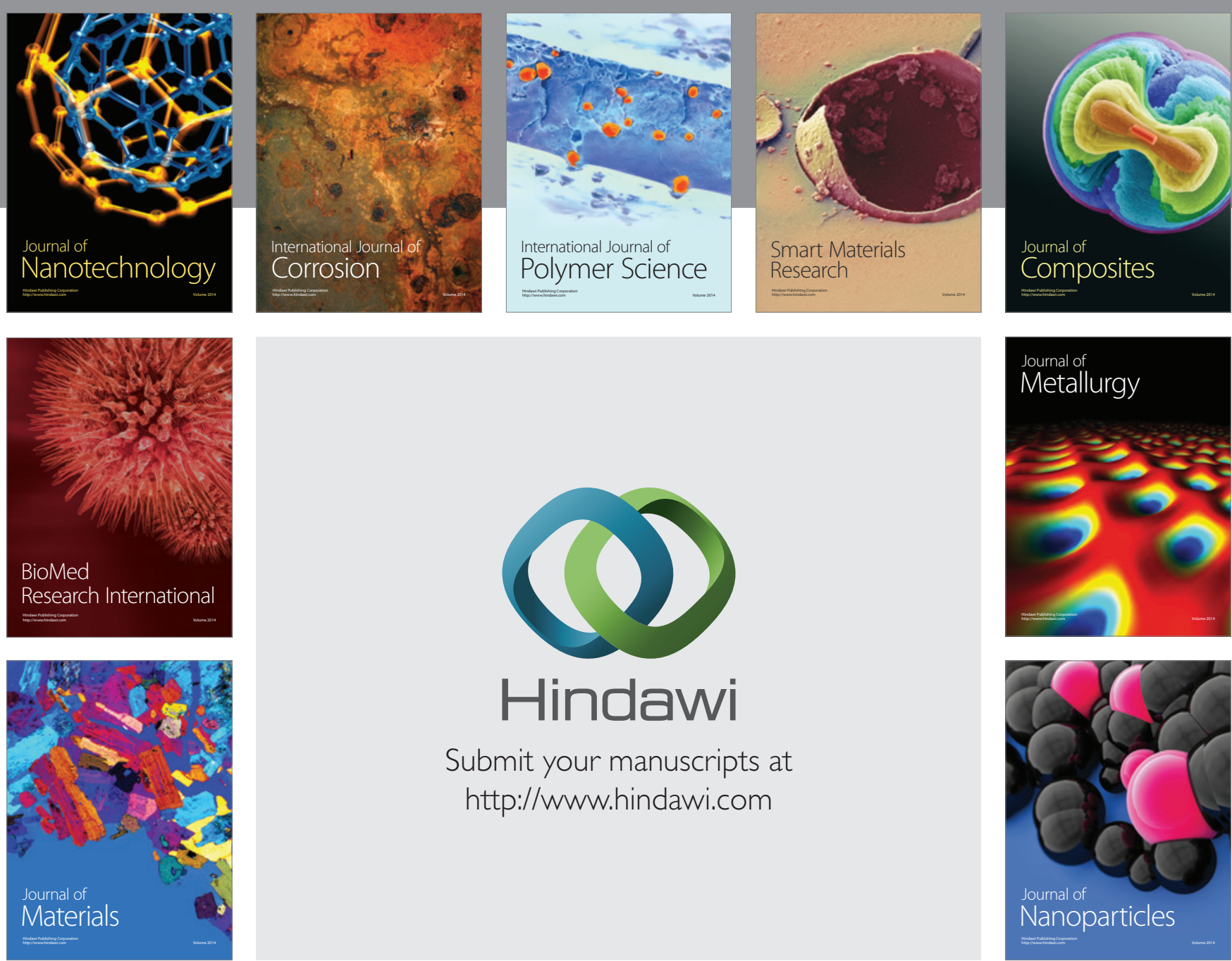

\section{Hindawi}

Submit your manuscripts at

http://www.hindawi.com

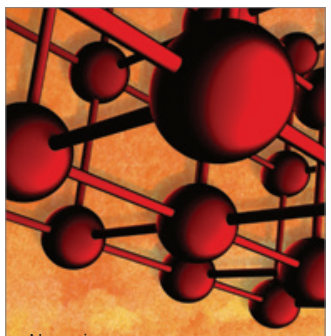

Materials Science and Engineering
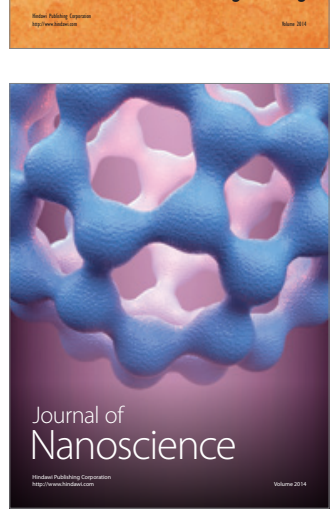
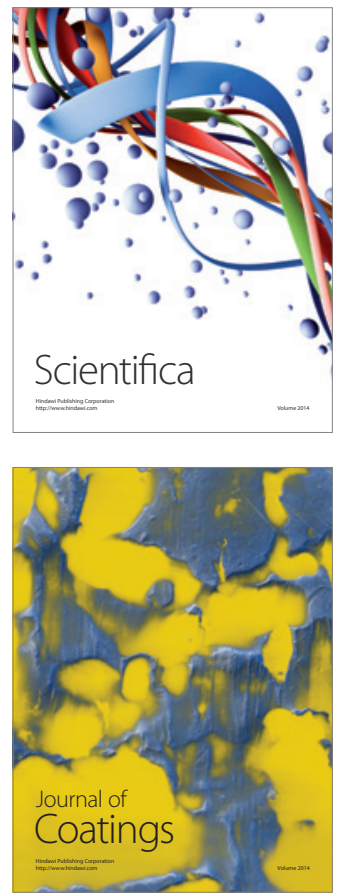
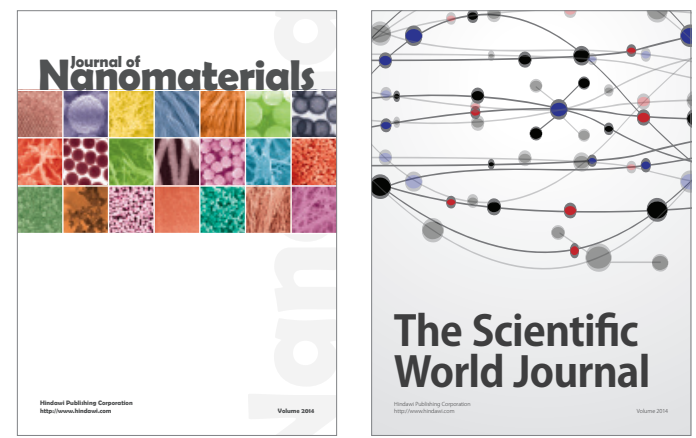

The Scientific World Journal
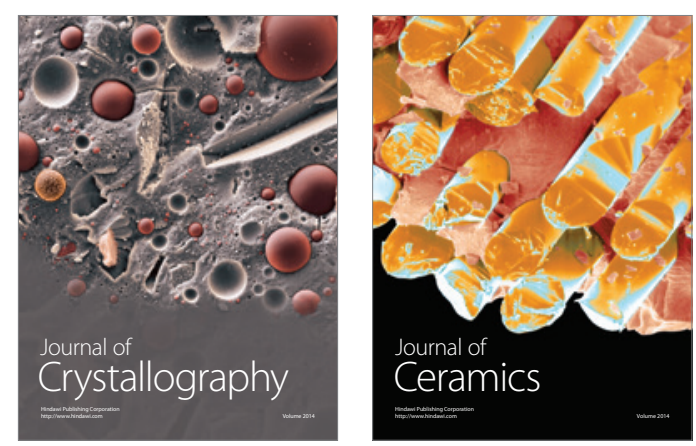
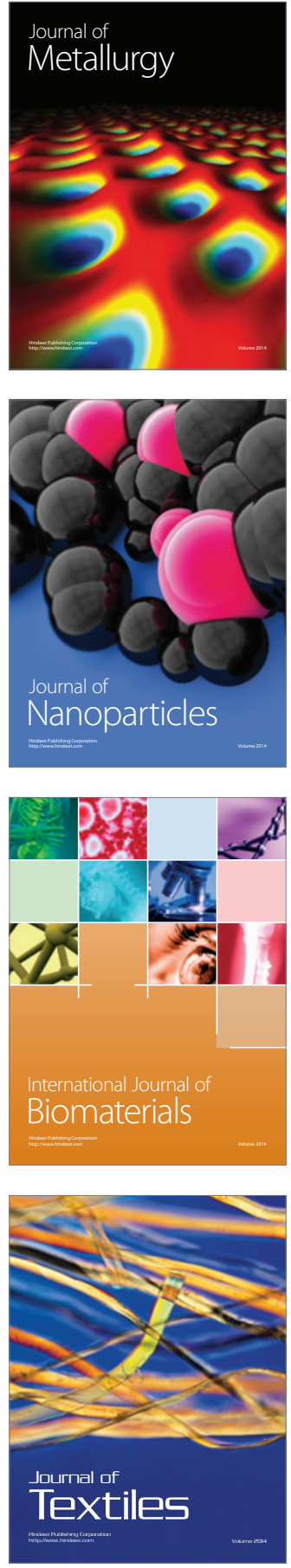